\title{
Wisdom of Vedanta for management educators of 21st century
}

\author{
Vidhu Gaur \\ Management Development Institute \\ Gurgaon (Haryana), India
}

\section{Keywords}

Pure Consciousness, Applied Consciousness, Spiritual Practices, Advaita Vedanta, ConsciousnessBased education

\begin{abstract}
There is a growing trend in business organizations to include spirituality in management. Spiritual values and practices are being used as management tools to realize full potential of employees, ethical practices, increasing productivity, better interpersonal relationships, and community services etc. Management educators are coming up with improved ways to embrace spirituality into the courses and the institutions. With inclusion of spirituality in the practices of management, educators need to develop model programs to teach spirituality and the methods to know the success of such programs. The ways of managing pure and applied spirituality without unravelling it from the other essentials of management education is a new challenge before educators. Vedanta emphatically declares the truth that we are paripurna or totally fulfilled, completely satisfied. For some reasons, we do not know it. Ignorance of our fullness causes an imaginary void. Desire arises in the mind to acquire and possess things to fill the void. Vedanta gives knowledge of our fullness. The population of young is highest in the world. They are in hurry in searching for the meaning of life. It is the era of 'Spiritual Youth'. The spirituality centres on meditation, going deeper into one's own self and harnessing the soul's energy. Practices of meditation has to be evolved looking to the younger generation and their specific characteristics. Lot of research work is needed in the direction of practical meditation and yoga looking to the present-day need. Management educators can teach students about the spirituality in life and in business too. Students can be motivated to understand deeply the Vedantic methods to experience the pure consciousness and analyse its applied aspects through the continuing research work. At present, traditional management institutes and universities are lacking such practices.
\end{abstract}

Corresponding author: Vidhu Gaur

Email addresses for corresponding author: vidhu.gaur@mdi.ac.in

First submission received: $13^{\text {th }}$ September 2017

Revised submission received: $24^{\text {th }}$ April 2018

Accepted: 25 th June 2018

\section{The Introduction}

We find many fast-growing changes in the present-day world. The major changing trends include: Dominance of science and technology and its electronic revolution affecting the massive change in people's actions and interactions, globalization of economy, new humanism to act against social injustice and exploitation collectively, and the upsurge of awareness in spirituality by practicing spiritual disciplines like meditation, prayer, yoga etc.

The present-day spiritual surge is the result of the normal psycho-social growth of human consciousness. Its followers are successful people like corporate executives, businessmen, engineers, doctors, and others. It is due to the autonomy and the ripeness of the human mind in its ongoing way of development. They understand that the benefits of the spiritual practices are well supported by science and technology. The common ground between science and spirituality is consciousness. Consciousness is the subject of research by many disciplines like philosophy, science, psychology etc.

Management education needs a consistent means to develop students directly from their inner richness. Spiritual-Based education develops students with creative intelligence and integrates education with a proper foundation. 
The outcomes of Consciousness-Based education have been unprecedented and scientifically verified. These outcomes include significant growth of intelligence, creativity, learning ability, field independence, ego development, and moral maturity, among others. These results are remarkable because many of these values typically plateau in adolescence-but Consciousness-Based education promotes this growth in students of all ages, developing potentials that otherwise would have remained unexpressed. Beyond this rich cognitive growth, Consciousness-Based education significantly reduces student stress, boosts selfesteem, improves health, reduces substance use, and enhances interpersonal relationships. All of this comes together to create exceptional learning environments. This approach even measurably improves the quality of life in the surrounding society (Pearson, 2011).

The main components of Spirituality-Based education may consist: Theoretical understanding of consciousness, developing the potential of students from within, and promoting effective learning. Student understanding depends on his level of alertness or consciousness. More alert, the more thriving the learning. Better the understanding of pure spirituality, the better the applied in decisions and communications.

Academic disciplines explore one facet of our world and such compartmentalizing knowledge is found inadequate to face the challenges of problems of the real world. For comprehensive looking at issues, all academic disciplines immerge from human consciousness. If the fundamental principles of spirituality or consciousness are understood clearly, then one can grasp all human knowledge comprehensively. An effortless procedure for allowing the excitations of the mind to gradually settle down until the least excited state of mind is reached. This is a state of inner wakefulness, with no object of thought or perception, just pure consciousness, aware of its own unbounded nature. It is wholeness, aware of itself, devoid of differences, beyond the division of subject and object-transcendental consciousness. It is a field of all possibilities, where all creative potentialities exist together but yet unexpressed. It is a state of perfect order, the matrix from which all the Laws of Nature emerge (SchmidtWilk, 2011).

This theoretical and precise understanding of the pure consciousness - not as an abstract - but by direct personal experience enables one to achieve one's full potential. With this theoretical component as a foundation, educators and students share a complete understanding of individual development and make knowledge simpler and appropriate to the students. This paper highlights the theoretical understanding of pure consciousness in specific reference to Vedanta, the ancient wisdom of India.

Vedantic knowledge of Reality is called liberating knowledge. It is also called soteriological knowledge as it radically transforms man by making one free once and for all from ignorance, illusion, delusion, fear, and attachment.

\section{Main Body of the Paper}

Global impact of knowledge workers from India led to an acceptance of Indian management in western countries and it resulted in the popularity of yoga and meditation as tools of stress management in corporate houses. The western corporate sector adopted many practices in management which originated in India. Yoga, meditation, spirituality and consciousness have been the hot topics in today's western corporate world. Should then the management institutes of India not include the study of these indigenous terms in its management education system? The Consciousness-based education is the need of the hour and getting momentum in the elite management institutions of India.

The present-day managers and leaders are required to develop a balancing attitude among profit, people and planet. Wisdom constitutes the basic background to develop such a balance attitude. Earlier, professionals were required to focus on skills only. But, today is the need of 'enlightened professionals' to take us from a purely market oriented mission to development-oriented vision by giving appropriate stress on values and wisdom. It expands the boundaries of education paradigm. Earlier, management education was based on skills with great stress on tools and techniques approach. In later half of the last century, the human component received attention and human values got its place in the management education and the efficiency and effectiveness component dominated in the management thought. Now, in this century the phrases like enlightened organizations, corporations as institutions etc. are gaining popularity. Thus, with the development of skills, efficiency, and effectiveness, the component of enlightenment is being added in the new foundations of the management thought. There is a deep need to 
develop management education with enlightenment paradigm to develop management professionals with a new balance among market values or profit making, social values or developing happy employees/people, and spiritual values or developing human relationships.

\subsection{Understanding Consciousness and Spirituality}

Vedanta considers the human personality as trichotomous structure comprising of body, mind, and atman. The atman is known as sat-chit-ananda and also as soul or spirit in the Indian tradition. The phrase sat-chit-ananda means existence-consciousness-bliss. The atman is considered unchanging, eternal and immortal but the body and mind are considered ever changing and perishable. Atman is our true nature. Consciousness is the pure 'contentless' awareness, absolute self-awareness. Consciousness is transcendental reality which transcends the senses. Spiritual life is a life centred on spirit. Spirituality differs from religion by not emphasizing on dogmas, traditions or customs but on individual quest for direct transcendental spiritual experience. The study of consciousness was developed by the ancient Indian sages through the meditation and deep understanding. Vedanta has given the most complete understanding of consciousness to the humanity.

Ordinarily we see facts and not the reality. Seeing a tree, we see the facts of the tree like green colour, branches, leaves etc. We have to apply our understanding to know the whole tree by transcending the facts to perceive the roots of the tree which otherwise not seen by the senses. So, facts are known through senses but the using the discriminating mind we can know more than the senses. Reality is still subtler and cannot be grasped by the mind even. The real tree is more than our conception and covers the whole ecosystem of soil, air, sun, rain etc. and extends to energy system and waves of the Cosmos. One has to transcend the mind to know the reality as it does not open its secret to the level of mind. How to achieve such transcendence? Transcendence is to go to the root of the Self. It is the awakening to a subtler energy not conditioned by thoughts.

Vedanta provides the philosophy to study, contemplate, assimilate and apply it in one's life to evolve spiritually to reach the ultimate state of Self-realization or God-realization or to be one with the ultimate reality. Indian philosophy holds life as a spiritual process towards perfection. Self-perfection is the supreme value. Man has the capacity for self-transcendence. The supreme Godhead lies within one. One's ignorance veils his supreme self. Vedanta gives the knowledge to discover the Self. It is an exercise akin to medical treatment. When a disease seizes our body, we lose our original health. The doctor prescribes medicine to eradicate the disease. When the disease is removed, we regain our health. Health is our original state. Similarly, the Self is our original Being and ignorance is the disease. The knowledge of Vedanta removes ignorance to restore our Self to ourselves.

\subsection{Understanding Consciousness in View of Vedanta}

Every Indian school of philosophy holds, in its own way, that there is a direct realization of Truth. A man of realization enjoys total liberation from the strains, stresses and limitation of the terrestrial realm; one who fails to attain realization is entangled in them and is lost. The greater the understanding of the world of objects, the better shall be the relationship with it. With that right understanding if one approaches the world, it shall certainly yield a fuller satisfaction and with lesser chances of disillusionment and despair. The thesis that Vedanta propounds is that in hasty, unintelligent evaluation of life, of things and beings, one tends to make a wrong estimate of the world; by superimposing false values of things, and to suffer the consequent imperfections in experience. This pale vision of a misinterpreted world, which naturally doles out to ample share of sorrows is fully condemned by the wise seers in the Upanishads. They make a passionate appeal to man to make a right re-estimate of the world of objects.

Vedanta says that consciousness is the Real nature of human beings, and that evolution is completely fulfilled when this state is rediscovered, then certainly the path by which getting back of this lost status of Perfect Bliss must be sought for. As the path to the realization of Brahman, the Upanishads recommend the fourfold discipline: (1) cultivation of moral purity as well as the disposition and will to seek the liberating knowledge; (2) listening attentively to a teacher (guru, the liberated man); (3) reflecting upon the truths thus heard; and (4) meditation. Such practices help to gain more and more understanding about the futility of seeking some seeming-happiness or any eluding peace in the world of sense-objects. 
Sense control and reduction in the agitation of the mind further enables one to gain a thousand-fold more joy, peace and tranquillity within.

The ontological approach to reality has given rise to the different schools of Indian philosophy. Advaita Vedanta is a system of orthodox Indian philosophy which is unique in its nature, and in its method of discerning the ultimate reality. It says, though the ultimate reality is one without a second, there are two grades of existence, one absolute as svayamsiddha which is called parmarthika satta, and another pramana-siddha or having practical or factual or empirical existence called vyavaharika satta. Vedanta asserts that this seeming world of sense object is not real. This is only a finite appearance. It can be ended. The world is seemingly real to one just as the snake is real to the deluded, although there is really only a rope. Mirage can never be; even when one 'sees' the mirage, desert alone is the reality in it. Vedanta proclaims the phenomenality of the world.

Philosophy in India has sprung from the spiritual experience of the ancient sages; it is not the result of mere intellectual speculation. Since it aims at the knowledge of the Transcendental Reality, it is termed as Darsana, or 'Vision of Truth' in Sanskrit. Every Indian school of philosophy holds, in its own way, that there is a direct realization of Truth. Vedanta stands out as the clearest and most significant native philosophy of India. It answers at once strict demands of metaphysics and the deep requirements of a sound religion. Vedanta is the most comprehensive summary ever made of the perennial philosophy; hence its enduring value is meant not only for Indians, but also for all mankind.

The literal meaning of the term Vedanta is "the end of Vedas, the concluding parts of the Vedas, the culmination of the Vedic teaching and wisdom." Thus the term originally referred to the Upanishads, the last literary products of the Vedic period. However, Vedanta has subsequently come to include the various elaborations and interpretations of the Upanishads. In course of time, there emerged three principal schools of Vedanta: (1) Advaita (non-dualism) of Samkara, (2) Visistadvaita (qualified non-dualism) of Ramanuja, and (3) Dvaita (dualism) of Madhava. Without doing violence to the specific doctrines of the various Indian schools of philosophy, Samkara's Advaita Vedanta can be regarded as representing the Indian tradition in both thought and spirit (Chinmayananda, 2003).

For Epistemology, Samkara is an intellectualist. Intellectual intuition is based upon 'knowledge' (Jnana) and consequent upon 'reasoning' (Manana) and 'Meditation' (Dhyana). Ordinary sense perception and imagination cannot, according to Samkara bring us near to reality as they are not freed from ignorance. According to Samkara, there are only degrees of falsity and no degree of truth (Brahman being the sole 'Truth'). In his Advaita, things are in ascending order, containing lesser and lesser falsity, stand thus: World - God - Absolute or Brahman.

For the treatment of Ethics, Samkara holds extra-ordinary views about 'morality'. It is sometimes charged (though wrongly) that Advaitism is antagonistic to Ethics. For, in the view of Samkara, actions may be right or wrong - that is, - correct or incorrect, but not good or bad, moral or immoral. The true contention is, however, this that whatever is correct - must be moral (though not conversely always) and whatever is incorrect - must be immoral as resulting from ignorance. Thus Samkara lays down a very rigid code of morality that has a self-transcending goal.

Samkara accepts a theory of Causation - according to which the apparent effect is non-different from its cause - which latter has the sole reality. Brahman, being the ultimate Being, enjoys alone the eternity of existence - and all things else which appear as distinct from Brahman is not ultimately real. All the perceived things of the world may have empirical reality (Vyavaharika Satta) but they cannot have ultimate reality (Paramarthika Satta) which is possessed by Brahman alone. Samkara takes the principal of Non-contradiction (Abadhitatva) as the test of reality. The objects of ordinary illusion, having very low form of apparent existence (Pratibhasika Satta), are contradicted by the existence of empirical objects and those latter again are ultimately contradicted by the absolute existence of Brahman. Ignorance of the proper nature of Reality is cancelled by the knowledge of the same. The power of creating illusory shows - or Maya-Shakti is not existent in Pure Brahman. It is connected with Brahman - as God of the world, and not as Brahman, the ultimate reality. The Maya Shakti in God and the Ajnana-Shakti in the individual (Jiva), have two-fold functions (i) the concealment of the real nature of things (Avarana) and (ii) the projection of illusory things on the locus of real things (Viksepa). According to Samkara, the illusory objects are new creations of indeterminate character, being neither real nor unreal (Anirvacniyam) (Gaur, 2011). 


\section{Discussion and Conclusion}

Philosophical concepts must solve the problems of life of human beings. Present day modern society has three types of problems: economic; psycho-social; and existential. Providing necessities like food, clothing, comforts etc. fall under the economic problems. Mental problems of stressful living of modern life and social evils like violence, crime, drugs etc. fall under the psycho-social category of problems. Internal causes like meaninglessness of life, sense of guilt, feeling of loneliness, problems of love etc. arise from one's own existence and fall under the existential category of problems.

Science and technology are being used to solve economic problems in the world. The root-cause of existential problems lies deep in the human soul. These problems arise due to the isolation of the ego from its real source, atman, which is source of happiness, knowledge etc. The alienation of ego from atman is the main cause of all existential problems of modern society. The psycho-social problems can be solved by the combination of science and technology and the efforts made to solve the existential problems.

The transcendental aspect of consciousness is represented by the atman. Realization of transcendental consciousness has many benefits like: 1) eliminates existential problems, 2) provides a spiritual surge to attain everlasting joy and fulfilment, 3) provides a feeling of love by touching the deeper level of personality, and 4) enables one to face the mystery of death. Transcendent experience, hence, makes life meaningful, achieves a sense of fulfilment, and makes one to serve humanity with selfless love.

\subsection{Mathematical Model to Understand Super Consciousness}

Consciousness can be explored through three approaches: Experimental (being used by scientists), Expositional (belongs to philosophers), and Experiential (belongs to sages or mystics). Though there is no convergence among these fields but recent experiments on the brain of meditative people and recording the neuro-physiological changes have developed a hope of developing some common points among these three approaches of consciousness in near future.

Vedanta asserts that the entire universe was lying immersed in the beginning in the ocean of consciousness. Matter and spirit were one in the realm of such super consciousness.

Einstein's famous formula $\mathrm{E}=m c^{2}$ states that the equivalent energy of mass $(\mathrm{m})$ can be calculated with the help of the speed of light (c as $3 \times 10^{8} \mathrm{~m} / \mathrm{s}$ ). This mass-energy equivalence states that mass and energy are convertible. Physics says that in an atom electron move around the nucleus at very higher speeds. In the same way planets revolve around the sun in the solar system and similarly other stars move around their respective mother stars in the universe. In the volume of an atom only $10000^{\text {th }}$ part is matter and rest is space in which electron revolves round the nucleus. Such a less matter of an atom can also be bombarded to convert it into energy as shown practically by atom bombs. Let us imagine that all the matter of the universe is bombarded to convert the entire matter mass into the energy component then what would remain here? An existence with vast space and tremendous energy will remain. This existence can be taken as the state of Super Consciousness mentioned above. This is Advaita state out of which Dvaita (matter and spirit) emerges.

\subsection{The Secret of Perfect Relaxation - Vedantic Renunciation}

There is a principle that rest is the basis of activity. Everything in nature moves in cycles of rest and activity. If the hectic schedule of the present-day executives is followed by the deep rest and relaxation in sufficient intervals of time, they can be energized by this technique.

While at work, one can take short intervals of rest and devote those short intervals of a minute or so to the thought that the body is nothing, one never had anything to do with it (Vivekananda 1962). We are simply a witness; we have nothing to do with the consequences or the results of its actions. While contemplating in that way, one may close eyes, relax muscles, and keep the body perfectly at ease, unburden oneself of all thought. The more we succeed in taking off the burden of thought from our shoulders, the stronger we will feel. Let not perplexing thoughts and worrying ideas suck the sap of our life. The secret of perfect health and vigorous activity lies in keeping our mind always buoyant and cheerful, never worried, never hurried, never borne down by any fear, thought or anxiety.

Thus, Vedantic renunciation means throwing off and casting overboard all anxiety, fear, worry, hurry and trouble of mind by continually keeping before our mental vision the Godhead of our Real Self, exempt from all worldly cares, worries and duties (Chinmayananda, 2003). While at work our thought 
should be absolutely concentrated in it, un-distracted by anything whatever irrelevant to the matter in hand, but when the work is finished and there is no more occasion for the use of the machine, it must stop absolutely, stop entirely, no worrying - as if a group of boys were allowed to play their devilments with a locomotive as soon as it was in the shed - and the man must retire into the reign of the consciousness where his true Self dwells (Tirtha, 1978).

As an attitude of detachment, if for at least ten minutes every day in the morning or in the evening - we can consciously attempt to rest our mind, it can be revived from all its fatigue, and it can get re-charged with all its irresistible potentialities. Conscious rest is the secret of revitalizing an exhausted mind. Among the wondrous phenomena of this Universe, the human body appears to be the most unique self-repairing machine. Give rest to the body, it will correct itself; hence naturo-paths recommend long rest and fasting. There is no disease that the body cannot throw out by this direct method. Similarly, by giving "rest" to the mind-intellect equipment, it will revive itself; hence spirituo-paths (sages) recommend long rest and mediation. There is no illness that the mind cannot shake off by this subtle process (Tirtha, 1978).

\subsection{Conclusion}

Human life has been made extremely complex where difficulties and problems challenging us from all walk of life. There are people who are struggling to sort out their inner world for a meaningful life. Attaining inner peace is not easy because it means replacing old, ingrained habits that do not contribute to it with new ones that do. To keep any organization dynamic, healthy, and productive the managerial personnel must have an insight into the deeper aspects of human motivation in order to harness all the potentialities of the employees, both for the individual's growth and the growth of the organization. They should be the source of creative ideas. They should be conscious of the desires, aspirations, needs, and problems of their community, and should have the ability to dispassionately look at, understand and evaluate events and people not only from the material point of view, but from the psychological and spiritual points of view as well. Above all, they must know the technique of right action through which they can prevent dissipation and disintegration of their own personalities and the personalities of their employees. Perfect Relaxation means throwing off and casting overboard all anxiety, fear, worry, hurry and trouble of mind by continually keeping before our mental vision the Godhead of our Real Self, exempt from all worldly cares, worries and duties. This is a state of 'non-doing' or perfect rest.

Management facts can be pulled down to the origin and the experiences of the classrooms and in the sessions of meditation can be analyzed to developing comfort and confidence and enhancing the interpersonal relationships. Consciousness-Based education identifies the dynamics of consciousness at practical work and at academic disciplines at every level. Management educators can motivate students how to make best use of dynamics of consciousness.

\section{Research limitations and direction for further research}

The paper is conceptual and do not provide the systematic plan of knowledge to be provided to the participants or employees for their specific needs. However, this can be designed to suit to the corporate house in particular cases. The paper refers only Vedanta, the prominent Indian scripture, for all its ancient perspective. There are two levels of spirituality - the first one is to gain common sense and develop a scientific temper about all things. The second level of spirituality centres on meditation, going deeper into one's own self and harnessing the soul's energy. Practices of meditation has to be evolved looking to the younger generation and their specific characteristics. Lot of research work is needed in the direction of practical meditation and yoga looking to the present-day need. This paper will serve as a background work for future researches in this direction.

\section{References}

Bhajanananda, Swami. (2015). Understanding consciousness. Kolkata: Ramkrishna Mission, pp. 45-104.

Bhajanananda, Swami. (2014). Spirituality and science of consciousness. Kolkata: Ramkrishna Mission, pp. 81-114.

Chakravarti, S. K. (2014). The Vedanta kesari. Chennai: Sri Ramkrishna Math. pp. 182-191.

Chatterjee, Shoutir Kishore. (2009). Human development. Kolkata: Print World, pp. 13-87.

Chinmayananda, Swami. (2006). Kindle life. Mumbai: Central Chinmaya Mission Trust. pp. 113-129.

www.jbrmr.com A Journal of the Academy of Business and Retail Management (ABRM) 
Chinmayananda, Swami. (2003). Practice of Vedanta. Mumbai: Central Chinmaya Mission Trust, pp. 12-32.

Chinmayananda, Swami. (2001). Vedanta in action. Mumbai: Central Chinmaya Mission Trust, pp. 11-35.

Chatterjee, Debashis, (2014). Timeless leadership. New Delhi: Wiley-India, pp. 113-121.

Gaur, Vidhu. (2011). Thesis: Reflections of Indian Philosophy in the Select Plays of Tennessee Williams with Special Reference to 'Vedanta'. Kota: University of Kota, pp. 1-267.

Gerald F. Gavanagh \& Mark R. Bandsuch. (2002). Virtue as a Benchmark for Spirituality in Business. Netherlands: Kluwer Academic Publishers, Journal of Business Ethics 38: 109-117.

Kalra, J. B. (2010). Self-motivation: management and motivating concept. Delhi: M. S. Marknet, pp. 127-190.

Kanoria, HP. (2015). Science and spiritual quest. Kolkata: Bhaktivedanta Institute, pp. 94-97.

Mathew L. Sheep. (2006). Nurturing the Whole Person: The Ethics of Workplace Spirituality in a Society of Organizations. Journal of Business Ethics (2006) 66: 357-375 Springer 2006, DOI 10.1007/s10551-006-0014-5.

Pearson, Craig. (2011). Introduction: consciousness-based education: a foundation for teaching and learning in the academic disciplines. Lowa: Consciousness-Based Books, pp. 1-2.

Radhakrishnan, S. (1989). Eastern religion and western thought. Delhi: Oxford University Press, pp. 351-354.

Schmidt-Wilk, Jane. (2011). Developing consciousness in organizations: the transcendental meditation program in business. Lowa: Consciousness-Based Books, pp. 143-180.

Sharma, AP. (1999). The meaning to know thyself. Delhi: Pustak Mahal, pp. 104-114.

Sharma, G. D. (2001), Management and the Indian ethos. New Delhi: Rupa \& Co., pp. 1-113.

Sharma, Shriram. (2011). Spectrum of knowledge. Mathura: Yug Nirman Yojana Trust, pp. 80-83.

Sharma, Shriram. (2013). The only solution to our all problems. Mathura: Yug Nirman Yojana Trust, pp. 3-39.

Sukh, Shammi. (2001). How to improve productivity for greater profits. Mumbai: Better Yourself Books, pp. 37-115.

Sunirmalananda, Swami. (2015). Insight into Vedanta. Chennai: Sri Ramkrrishna Matha, pp. 219-221.

Tejguru, Sirshree. (2007). Self encounter: transformation. New Delhi: Macmillan.

Tejguru, Sirshree. (2009). How to be ever successful. Pune: Tej Gyan Foundation, pp. 9-18.

Tejomayananda, Swami. (2003). Right thinking. Mumbai: Central Chinmaya Mission Trust.

Tirtha, Swami Rama. (1978). In woods of God realization - Vol. ii. Lucknow: Rama Tirtha Pratisthan, pp. 45-56.

Usha, Sis. B. K. (2002). Self managing leadership. Mt. Abu: Brahma Kumari's Literature Dept., pp. 1-125.

Vivekananda, Swami. (1962). Complete works. Calcutta: Advaita Ashrama. Vol. IV, p. 359-425.

Waite, Rob. (2009). The lost art of general management: life skills. Bhopal: Indra Publishing House, pp. 93-120. 